\title{
Indicador de atividade reflexiva e teoria fundamentada: o pensamento reflexivo na busca e no uso da informação'
}

\author{
Reflexive activity indicator and grounded \\ theory: reflexive thinking in information \\ seeking and using
}

Kelley Cristine Gonçalves Dias GASQUE²

\section{Resumo}

O referencial metodológico composto pelo Indicador de Atividade Reflexiva aplicado concomitantemente à Teoria Fundamentada permite identificar as ações e os tipos de pensamento ocorridos em determinado processo, isto é, possibilita verificar a ocorrência do pensamento reflexivo nos relatos dos sujeitos durante determinadas ações. O presente artigo apresenta a visão geral dos instrumentos metodológicos, bem como, propósitos, fases, procedimentos, critérios para avaliação e limitações. Por fim, o estudo exemplifica a utilização do referido referencial. Os resultados mostram que a maior parte do pensamento empregado na busca e no uso da informação é do tipo não-reflexivo. As relações percebidas nessa pesquisa são de natureza multirreferencial, o que requer instrumentos interdisciplinares na resolução do problema.

Palavras-chave: Busca de informação. Uso da informação.

\begin{abstract}
The methodological approach, consisting of the Reflexive Activity Indicator concurrently applied to Grounded Theory, allows for theidentification of the actions and types of thought occurring in a particular case, making it possible to verify the occurrence of reflexive thinking in reports of the subjects during determined actions. This article presents an overview of methodological tools, as well as goals, phases, procedures, evaluation criteria, and limitations. Finally, it exemplifies the use of that benchmark. The results show that most of the thinking used in information seeking and using is of the non-reflexive type. The relationships perceived in this research are of a multi-referential nature, which requires interdisciplinary tools to solve the problem.
\end{abstract}

Keywords: Information search. Information using.

\section{Introdução}

Os estudos de comportamento informacional investigam as atividades de busca, uso e transferência de 
competências específicas, denominado'letramento informacional'. Das primeiras pesquisas, na década de 1950, aos dias atuais, observa-se uma evolução no enfoque dos estudos, de uma perspectiva mais restrita para outra mais abrangente, no que se refere aos conceitos, metodologias e grupos de usuários estudados, refletindo-se na mudança da terminologia adotada para definir o tópico, que passa de "estudos de usuários" ou "necessidades e uso de informação" para "comportamento informacional de usuários". Mais do que exercício tautológico, constitui-se em uma transformação paradigmática, que implica em novas maneiras de abordar e investigar o tópico (Gasque, 2008). Ao reconhecer que os indivíduos se inserem em um contexto complexo, múltiplo, sobreposto e dinâmico, Courtright (2007) enfatiza a necessidade de usar novas metodologias e múltiplos métodos de investigação.

O presente artigo apresenta relato de pesquisa exploratória, com enfase no referencial metodológico, utilizado para identificar o tipo de pensamento dos pesquisadores em formação, estudantes de mestrado e de doutorado, nos processos de busca e de uso da informação na comunicação científica, qual seja, o "Indicador de Atividade Reflexiva" aplicado concomitantemente à "Teoria Fundamentada". Para tanto, selecionou-se amostra de estudantes na etapa final dos cursos de antropologia, educação, geologia, matemática, nefrologia e sociologia, abrangendo sujeitos das três principais divisões do conhecimento, nomeadamente ciências exatas e naturais, ciências sociais e humanas, artes e humanidades. Os dados foram coletados por meio de entrevistas com 13 pesquisadores em formação, oriundos de cursos da Universidade de Brasília (UnB) e da Universidade de São Paulo avaliados com notas 6 e 7 pela Coordenação de Aperfeiçoamento de Pessoal de Nível Superior (CAPES). Posteriormente, houve a inclusão dos cursos de educação da UnB e da Pontifícia Universidade Católica do Paraná (PUCPR), devido ao grau de contribuição das reflexões apresentadas.

O "Indicador de Ensino Reflexivo", proposto por Zeichner e Liston (1985), é denominado nessa pesquisa de "Indicador de Atividade Reflexiva". Permite a análise do pensamento do sujeito sobre a ação ocorrida, de acordo com quatro categorias principais: discurso factual, discurso prudencial, discurso justificativo e discurso crítico. Por sua vez, os procedimentos da teoria fundamen- tada nos dados, segundo Strauss e Corbin (c1990), objetivam identificar, desenvolver e relacionar conceitos a partir dos dados coletados com o propósito de gerar uma teoria e não meramente descrever um fenômeno.

Apresentam-se os Indicadores de Atividade Reflexiva, bem como os objetivos, fases, procedimentos, critérios para avaliação e limitações da teoria Fundamentada, visto que o uso desses métodos de pesquisa pode ser adaptado aos estudos de diversos fenômenos, em especial, os de natureza mental, exploratória e indutiva para o desenvolvimento de teorias "conceitualmente densas", ou seja, com muitas relações conceituais (Glaser; Strauss, c1967, p.31).

\section{Indicador de atividade reflexiva}

O pensamento reflexivo é uma estratégia cognitiva que possibilita a compreensão mais profunda de fenômenos e processos, por meio da percepção das relações, da identificação dos elementos envolvidos, da análise e interpretação dos sentidos e significados, potencializando o processo de aprendizagem. De acordo com Dewey (1979), o ato de pensar reflexivo deve consistir em um fim educacional, como um processo que dura a vida inteira. A reflexão possibilita transcender a ação puramente impulsiva e rotineira por meio do planejamento, tendo em vista um agir deliberado e intencional para se atingir objetivos futuros. Na presente pesquisa, buscou-se verificar se as atividades de busca e uso da informação realizadas pelos pesquisadores em formação - mestrandos e doutorandos - no processo de pesquisa são reflexivas.

As investigações realizadas sobre a ocorrência da reflexão em atividades específicas são escassas, e parecem se situar, em sua maioria, no contexto educacional, por exemplo, os estudos de Zeichner e Liston (1985); Silva e Duarte (2001; 2002), que utilizaram o"Indicador de Ensino Reflexivo" de Zeichner e Liston (1985) para verificar a qualidade do pensamento produzido pelos docentes. Nesses casos, realiza-se a análise do discurso do sujeito, de acordo com quatro categorias principais: discurso factual, discurso prudencial, discurso justificativo e discurso crítico.

Embora o instrumento de análise do conteúdo do discurso tenha surgido no contexto educacional, pode ser transposto para qualquer tipo de atividade, sendo, 
nesse caso, denominado "Indicador de Atividade Reflexiva". As quatro categorias e subcategorias para análise do pensamento são:

a) Discurso Factual: caracterizado pela descrição dos fenômenos ocorridos em situações de busca e de uso da informação, isto é, o que ocorre, o que ocorreu ou deveria ter ocorrido, por exemplo: "Eu refinei o tema da pesquisa a partir das leituras que fizemos nos encontros com o próprio orientador, no contato com outros trabalhos".

Nessa categoria, distinguem-se quatro subcategorias: discurso descritivo, discurso informativo, discurso hermenêutico e discurso explicativo/hipotético. Somente a subcategoria de discurso explicativo/hipotético indica pensamento reflexivo.

- Discurso descritivo: descreve os detalhes ou características dos fenômenos observados.

- Discurso informativo: identifica informação relevante para o fenômeno, embora este não seja verificável por observação direta da atividade.

- Discurso hermenêutico: focado sobre os significados atribuídos pelo sujeito aos acontecimentos e atividades em análise.

- Discurso explicativo/hipotético: identifica as relações de causa e efeito na ocorrência dos eventos.

b) Discurso prudencial: caracterizado por sugestões e conselhos referentes às ações; assim como por avaliações sobre a atividade ou qualidade das ações desenvolvidas pelo sujeito, sem que seja fornecida justificação para ações sugeridas, por exemplo, "Hoje, eu tenho uma visão direcionada, posso dizer que eu sei o queéum processo depesquisa".

Distinguem-se quatro subcategorias: (De acordo com os autores, nenhuma destas subcategorias revela pensamento reflexivo).

- Instrução: identifica-se com sugestões para que o sujeito tente um determinado procedimento ou perspectiva, sem que seja fornecida justificação para tal.

- Conselho/opinião: consiste numa sugestão para que o sujeito considere dois ou mais cursos de ação, sem proporcionar justificação para as ações sugeridas.

- Avaliação: é um julgamento, positivo ou negativo, sobre o valor, trabalho ou qualidade de uma ação sem que seja fornecido suporte justificativo.
- Apoio: caracteriza-se por expressões de empatia, de encorajamento emotivo relativa a uma ação passada, presente ou futura.

c) Discurso justificativo: Caracteriza-se por identificar os motivos e racionalidade subjacentes às condutas do sujeito. Relaciona-se com a consideração de questões do tipo: o que fundamenta esta ação ou decisão? Um exemplo desse discurso é: "Eu acessava o Lattes para vero que os pesquisadores estavam produzindo de mais atual, aquelas pessoas queescrevem mais na nossa área, paraver se eu não estava aquém do que estava sendo produzido".

Divide-se em três subcategorias, classificadas de acordo com o tipo de racionalidade que constitui a justificação para a ação desenvolvida. Todas as subcategorias são consideradas como indicadoras de pensamento reflexivo.

- Racionalidade pragmática: emprega critérios que indicam o que é efetivo ou eficiente numa situação. A ação é justificada com base na sua eficácia para assegurar um resultado pretendido.

- Racionalidade intrínseca: justifica a ação com base no conhecimento e valores universais.

- Racionalidade extrínseca: justifica a ação com base em critérios externos à situação em análise e à ação presente (ex:: de potencial valor para a sociedade).

d) Discurso crítico: avalia a adequação das razões oferecidas no domínio do discurso justificativo, assim como valores intrínsecos, inerentes à estrutura e conteúdos, como exemplificado na frase, "a monitoração de informações por meio das citações pode oferecer mais subsídios do que simplesmente fazer buscas em bancos de dados. No primeiro caso, sabemos quem cita quem e como esse autor avalia os outros".

São quatro as subcategorias do discurso crítico. Três correspondem às subcategorias do discurso justificativo: pragmático, intrínseco e extrínseco. A quarta subcategoria relaciona-se com a prática curricular (ex.: currículo oculto). Nesse caso, será considerada a avaliação do sujeito em relação à adequação do currículo para o desenvolvimento da capacidade de buscar e usar a informação. As quatro subcategorias deste tipo de discurso são consideradas indicadores de atividade reflexiva.

Assim, as categorias para análise do pensamento revelam dois tipos de discursos: o não-reflexivo (factual e 
prudencial) e o reflexivo (Factual - explicativo/ hipotético, justificativo e crítico) (Zeichner; Liston, 1985).

Em linhas gerais, é contabilizada uma Unidade de Pensamento (UP) e classificada na respectiva categoria, quando for possível identificar as categorias principais e a subcategoria explicativo/hipotética no discurso dos pesquisadores iniciantes. Em seguida, são contabilizadas as unidades de pensamentos identificadas em cada uma das categorias a serem agrupadas nos dois tipos de discurso, conforme sua natureza reflexiva ou não reflexiva.

Os resultados da análise de conteúdo efetuados a partir dos discursos dos entrevistados sobre a busca e o uso da informação, de acordo com Tabela 1, permitem comparar os tipos e categorias de discursos utilizados nas atividades informacionais.

Observa-se que a maior entrevista consta de 201 UP e a menor de 82 UP. A análise de conteúdo do discurso dos pesquisadores em formação revelou a categoria factual, do tipo não-reflexivo a mais utilizada. Constituem-se exemplos desse discurso:

\begin{abstract}
Usei bastante a Internet como índice. É a primeira fonte, mas é uma coadjuvante. Não é uma fonte principal. Eu lia alguns artigos, acesso sites de busca e coloco autor ou assunto (Entrevistado 3 - Discurso factual).

Se você estiver fazendo um trabalho sobre comunicação e repositório institucional é interessante citar alguém que deu início ao repositório institucional pela primeira vez, o pioneiro (Entrevistado 12 - Discurso prudencial).
\end{abstract}

Quanto ao tipo de discurso reflexivo, a categoria predominante foi a justificativa. Houve raras incidências do discurso crítico, apenas 7 UP, como mostram os depoimentos a seguir:

Quem espera ir para o doutorado tem que publicar eapresentar trabalhos. Existe essa pressão do ponto de vista profissional! Eu também tenho pretensões

Tabela 1. Comparativo do tipo de discurso dos pesquisadores participantes (USP, UnB e PUCPR).

\begin{tabular}{|c|c|c|c|c|c|}
\hline \multirow{2}{*}{ Participantes } & \multicolumn{2}{|c|}{ Discurso não-reflexivo } & \multirow{2}{*}{ Factual (Explicativo/hotético) } & \multicolumn{2}{|c|}{ Discurso reflexivo } \\
\hline & Factual & Prudencial & & Justificativo & Crítico \\
\hline Entrevistado $1(\mathrm{UP}=112)$ & 62 & 15 & 0 & 34 & 1 \\
\hline$\%$ & & & & 31,25 & \\
\hline Entrevistado $2(\mathrm{UP}=166)$ & 118 & 19 & 6 & 23 & 0 \\
\hline$\%$ & & & & 17,5 & \\
\hline Entrevistado $3(\mathrm{UP}=90)$ & 73 & 2 & 13 & 2 & 0 \\
\hline$\%$ & & & & 16,7 & \\
\hline Entrevistado $4 \quad(\mathrm{UP}=104)$ & 83 & 11 & 3 & 7 & 0 \\
\hline$\%$ & & & & 9,7 & \\
\hline Entrevistado $5 \quad(U P=111)$ & 70 & 15 & 3 & 23 & 0 \\
\hline$\%$ & & & & 23,5 & \\
\hline Entrevistado $6 \quad(U P=201)$ & 110 & 24 & 5 & 62 & 0 \\
\hline$\%$ & & & & 33,4 & \\
\hline Entrevistado $7(\mathrm{UP}=100)$ & 5 & 11 & 1 & 33 & 0 \\
\hline$\%$ & & & & 34 & \\
\hline Entrevistado $8(\mathrm{UP}=124)$ & 61 & 8 & 0 & 49 & 6 \\
\hline$\%$ & & & & 44,4 & \\
\hline Entrevistado $9(\mathrm{UP}=82)$ & 58 & 6 & 1 & 17 & 0 \\
\hline$\%$ & & & & 22 & \\
\hline Entrevistado $10(\mathrm{UP}=100)$ & 67 & 14 & 1 & 23 & 0 \\
\hline$\%$ & & & & 24 & \\
\hline Entrevistado $11 \quad(\mathrm{UP}=126)$ & 89 & 12 & 5 & 20 & 0 \\
\hline$\%$ & & & & 19,9 & \\
\hline Entrevistado $12(\mathrm{UP}=148)$ & 106 & 15 & 1 & 26 & 0 \\
\hline$\%$ & & & & 18,3 & \\
\hline Entrevistado $13(\mathrm{UP}=137)$ & 109 & 8 & 1 & 19 & 0 \\
\hline$\%$ & & & & 14,6 & \\
\hline
\end{tabular}

Fonte: Gasque (2008, p.182).

Nota: USP: Universidade de São Paulo; UnB: Universidade de Brasília; PUCPR: Pontifícia Universidade Católica do Paraná. 
de denúncia, de fazer com que o meu trabalho possa ajudar a transformar essas questões. Porisso, divulgar é muito importante, porque quero relatar como as coisas acontecem e por quais razões (Entrevistado 6 - Discurso justificativo).

Alguma coisa tinha que fazer na biblioteca, porisso carreguei esse negócio de ir para a biblioteca na graduação também, pois a Internet não era tão difundida e tinham poucos computadores. Eu não tinha computador em casa, porisso usava a biblioteca e ia atrás de livros (Entrevistado 4 - Discurso explicativo/hipotético).

Em história, aprendemos que mais importante é preciso contemplar a estrutura acadêmica do texto com a criatividade, em que se consiga fazer um diálogo do presente com o passado, por exemplo, em termos de linguagem. Pra mim, foi importante ter feito esses dois cursos, porque você aprende tanto a lidar com uma perspectiva mais normativa, mais clássica, mais tradicional quanto essa perspectiva mais aberta de entender o texto numa dinâmica mais cultural, mais política (Entrevistado 8 - Discurso crítico).

O uso do "Indicador de atividade reflexiva" permitiu identificar o discurso dos mestrandos e doutorandos sobre a prática de pesquisa como predominantemente do tipo factual, não reflexivo. Isso mostra que os pesquisadores em formação realizam as atividades de pesquisas sem compreendê-las adequadamente. Considerando que, em geral, os alunos não possuem atividades de pesquisas na educação básica e ensino superior sistematizadas e ensinadas por meio de estratégias de ensino-aprendizagem adequadas é compreensível que seja assim.

Após a identificação do tipo de pensamento, os dados foram tratados e codificados pelos procedimentos propostos pela Teoria Fundamentada para o desenvolvimento da teoria sobre a busca e uso da informação pelos pesquisadores em formação.

\section{Teoria fundamentada}

A Teoria Fundamentada (Grounded Theory) é "um método geral de análise comparativa [constante]" (Glasser; Strauss, c1967, p.viii), daí ser frequentemente citada como método comparativo constante, com três objetivos definidos. O primeiro, proporcionar uma base lógica para a teoria com a intenção de contribuir para "fechar a lacuna entre teoria e pesquisa empírica" (p.vii). O segundo, propor padrões e procedimentos mais adequados para descoberta da teoria. E por último, validar a pesquisa qualitativa como método adequado e específico designado para gerar uma teoria.

A Teoria Fundamentada é uma metodologia geral, aplicável tanto a estudos qualitativos quanto a quantitativos. Nesse sentido, Glaser e Strauss (c1967, p.17) afirmam que "toda forma de dados é útil tanto para a verificação quanto para a geração de teorias, qualquer que seja a ênfase [...]". Esta depende das circunstâncias de pesquisa, dos interesses e treinamento do pesquisador e dos tipos de materiais necessários para a teoria.

Por ser uma metodologia relativamente recente utilizada nos estudos de busca e uso da informação, optou-se por proporcionar um detalhamento maior de seus fundamentos. No próximo tópico, são apresentadas a visão geral de sua origem, bem como as fases, procedimentos, contribuições e limitações.

\section{Origens da teoria fundamentada}

Gasque (2007) realizou ampla revisão de literatura sobre a Teoria Fundamentada considerando, em especial, as obras de Strauss e Corbin. Descreve que a referida teoria se originou do interacionismo simbólico ${ }^{3}$ e da estatística positivista, linhas de pensamento referentes às posturas filosóficas e à formação dos dois sociólogos, Anselm Strauss e Barney Glaser. O primeiro, admirador das ideias de Robert E. Park, W. I. Thomas, John Dewey, G. H. Mead, Everett Hughes e Hebert Blumer, inspira-se no interacionismo e pragmatismo. O segundo, influenciado por Paul Lazarfelds, conhecido como inovador dos métodos quantitativos).

Para Alvesson e Sköldberg (2000), o interacionismo simbólico foi a base mais importante para a construção da Teoria Fundamentada, não sendo, porém, a única fonte de inspiração. Glaser usou como modelo o método de análise estatística, integrando a forma positivista com a qualitativa. Por conseguinte, o positivismo estatístico, herdado do programa de pesquisa de Lazarsfeld, em que os dados constituem o princípio e o fim do processo

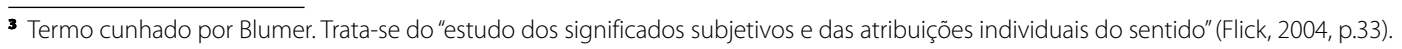


científico, proporciona uma abordagem mais rigorosa (Gasque, 2007).

Glaser e Strauss (c1967) argumentam que existem crenças de que a aplicação das teorias formais fornece os conceitos e hipóteses necessárias à explicação do fenômeno. Nesse caso, a tendência é que o pesquisador tente ajustar os dados aos pressupostos teóricos, deixando de observar, muitas vezes, conceitos e hipóteses que poderiam surgir. Em contraposição, na Teoria Fundamentada, o pesquisador constrói a teoria a partir da observação específica do fenômeno e não pela aplicação de uma teoria pré-estabelecida para explicá-lo. O propósito é desenvolver uma teoria e não meramente descrever um fenômeno, como elucidam Strauss e Corbin (c1990, p.23):

Uma Teoria Fundamentada é aquela derivada indutivamente do estudo do fenômeno que representa. Isto é, ele é descoberto, desenvolvido, e provisoriamente verificado por meio de sistemática coleta e análise de dados. Portanto, a coleta de dados, análise e teoria possuem relação recíproca entre si. Não se começa com uma teoria para prová-la. Começa-se com uma área de estudo em que se permite a emersão do que é relevante.

\section{Etapas da teoria fundamentada}

O modelo do processo de pesquisa na Teoria Fundamentada apresenta uma interdependência e encadeamento circular das partes em que as atividades ocorrem simultaneamente. Nesse processo, incluem-se três etapas principais - a amostragem teórica, a codificação e a redação da teoria - abordadas a seguir.

- Amostragem teórica: refere-se ao processo de coleta de dados para a geração da teoria. Glaser e Strauss (c1967) explicam que nessa primeira fase, o analista deve coletar, codificar e analisar conjuntamente os dados, identificando aqueles que serão coletados em seguida e onde encontrá-los para fundamentar a teoria emergente. Esse processo é controlado pela teoria em formação (Gasque, 2007)

Flick (2004) argumenta que nessa abordagem, as experiências e conhecimentos do pesquisador devem ficar em "estado de suspensão" para que a teoria possa emergir. Isso significa que se deve-estar aberto ao novo e ao inesperado. Isso porque apesar de o pesquisador possuir conhecimento teórico sobre o objeto que aborda, somente conhecerá a relevância de cada elemento do objeto de estudo em determinado contexto ao longo do processo de pesquisa

Gasque (2007) descreve que os dados devem ser coletados, codificados e analisados sistemática e simultâneamente até a saturação teórica, ou seja, até que dados novos ou relevantes não sejam mais encontrados ou que comecem a se repetir. Ressalta sobre a importância de se utilizar a"sensibilidade teórica", compreendida por Strauss e Corbin (c1990), como a destreza para olhar os dados com perspicácia e imaginação, com o objetivo de verificar a relevância dos dados e discernir o que é ou não é pertinente ao estudo).

Um ponto básico da amostragem teórica diz respeito à seleção da amostra, cuja representatividade é garantida por sua relevância. Os critérios de seleção não se baseiam nas técnicas usuais como amostragem aleatória ou estratificação, mas pelos insights que se acredita que uma pessoa possa trazer para o desenvolvimento da teoria. Assim, questões como "Quais grupos ou subgrupos de populações, eventos, atividades, devemos interpelar? E com quais objetivos?" (Strauss, 1987, p.38) são decisões cruciais para a Teoria Fundamentada.

Muitas técnicas de coleta de dados podem ser utilizadas na Teoria Fundamentada, dentre elas, a observação participante, entrevistas, discursos, cartas, biografias, autobiografias, pesquisa na biblioteca. Contudo, independente do método utilizado para coletar os dados, sublinha-se que a abordagem se concentra firmemente na interpretação dos dados. Após a estratégia para a coleta de dados, que acontece de forma gradual, estes são utilizados para os procedimentos de codificação.

- Codificação: refere-se ao tratamento dos dados realizado mediante ainterpretação de dados. Constitui-se de procedimentos para rotular e analisar os dados coletados, sendo definida de acordo com Strauss (1987, p.21), como"o termo geral para conceitualização de dados; assim, os códigos abrangem questões nascentes e oferecem respostas provisórias sobre categorias e seus relacionamentos".

Flick (2004) argumenta que as comparações constantes entre fenômenos, casos e conceitos, procedi- 
mentos relativos à codificação dos dados, permitem o desenvolvimento de teorias por meio da abstração e relações entre os elementos. Os objetivos dos procedimentos de codificação, enumerados por Strauss e Corbin, (c1990) são: construir/gerar uma teoria ao invés de verificá-la; prover aos pesquisadores ferramentas analíticas "rigorosas" para se fazer uma pesquisa de qualidade; auxiliar os pesquisadores a lidarem com os preconceitos e concepções prévias ou que podem ser desenvolvidos durante o processo de pesquisa e prover uma fundamentação densa e desenvolver a sensibilidade e integração necessárias à geração de uma teoria exploratória, rica e rigorosa, que se aproxime da realidade que representa.

Os procedimentos de codificação são denominados de codificação aberta, codificação axial e codificação seletiva, que devem ser entendidos como formas diferentes de tratar os dados, muito mais do que etapas firmemente demarcadas, claramente distintas e temporalmente separadas (Strauss, 1987).

- Codificação aberta: refere-se ao processo de identificação e análise dos conceitos, considerando as suas propriedades (atributos ou características pertencentes a uma categoria) e dimensões (localizações das propriedades dos dados ao longo de um continuum). Para tanto, envolve as atividades de quebrar, examinar, comparar, conceituar e categorizar os dados, os quais serão sumarizados em uma lista de códigos (rótulos oriundos do processo de análise dos dados) e categorias (compreende uma classificação de conceitos descoberta por meio da comparação entre os conceitos pertencentes a um fenômeno similar) originadas dos rótulos atribuídos livremente a cada frase, linha ou parágrafo (Strauss; Corbin, c1990).

Precisão e especificidade, características fundamentais dos conceitos, podem ser obtidas por meio das comparações e questionamentos, procedimentos básicos da codificação analítica na codificação aberta. Para rotular os dados, utilizam-se as perguntas e comparações em busca de similaridade e diferenças entre cada incidente, evento ou situação: "O que é isto? O que representa?" (Strauss; Corbin, c1990, p.63). Os eventos e incidentes semelhantes são comparados e agrupados para formar categorias (Gasque, 2007).
A integração de outros conceitos e subcategorias agrega às categorias força conceitual, as quais podem ser mais precisas, quando suas propriedades são classificadas e dimensionadas ao longo de um continuum. Ao final desse processo, obtém-se uma lista de códigos e categorias, que deve ser complementada pelas notas em código - memorando - criadas para explicar e definir o conteúdo dos códigos e categorias (Strauss; Corbin, c1990).

- Codificação axial: é o processo de identificar as categorias mais relevantes e inseri-las como fenômeno central para estabelecer as relações entre as categorias e subcategorias. Essa etapa pode ser compreendida como aprimoramento e diferenciação das categorias resultantes da codificação aberta. Para tanto, de acordo com Strauss e Corbin (c1990, p.96), torna-se necessário recorrer ao paradigma de codificação:

A codificação axial é um conjunto de procedimentos após a codificação aberta em que os dados são colocados em uma nova forma, por meio das relações entre as categorias. Isto é realizado com o paradigma de codificação que envolve condições, contexto, estratégias de ação/interação e suas consequências.

Essa etapa torna possível a sistematização dos dados por meio das relações entre as categorias e subcategorias com a utilização dos termos: A) Condições causais; B) Fenômeno; C) Contexto; D) Condições intermediárias; E) Estratégias de ação/interação e F) Consequências (Strauss; Corbin, c1990, p.99).

- Codificação seletiva: relaciona-se à integração e ao refinamento das categorias em nível mais abstrato. Nessa fase, terceira e última etapa da codificação, identifica-se a categoria essencial em torno da qual as outras categorias desenvolvidas podem ser agrupadas e integradas. "O fenômeno central é o coração do processo de integração" (Strauss; Corbin, c1990, p.124).

Para tanto, o primeiro passo envolve a formulação ou elaboração da "história do caso" com o objetivo de oferecer um breve panorama geral descritivo. Depois, faz-se necessário mover da descrição para a conceitualização por meio da elaboração da "linha da história". Assim, tanto na codificação aberta quanto na axial, os fenômenos são nomeados para que nessa fase o pesquisador possa olhar a lista de categorias e avaliar qual delas é abstrata o sufi- 
ciente para englobar todas as outras descritas na história. O resultado deve ser uma categoria central juntamente com as categorias relacionadas a ela. Portanto, o pesquisador deverá escolher entre dois ou mais fenômenos igualmente salientes (Strauss; Corbin, c1990, p.120).

A categoria central é essencial para a integração de todos os elementos da teoria, pois é a partir dela que as propriedades e dimensões devem ser identificadas. Após essa etapa, novamente deve-se empregar o paradigma - condições, contexto, estratégias e consequências - nas relações entre as categorias (Strauss; Corbin, c1990).

As várias fases da Teoria Fundamentada ocorrem simultaneamente, permitindo ao pesquisador fazer as modificações necessárias no transcorrer do processo. 0 procedimento de retroalimentação constante com os indivíduos da pesquisa possibilita entender melhor o fenômeno estudado. Assim, à medida que os dados são coletados e analisados, surgem outros que direcionarão as novas coletas, produzindo categorias mais refinadas até a saturação.

Após a finalização da análise dos dados, o próximo passo da teoria é o registro da teoria, isto é, a redação.

- Redação da teoria: ao longo do processo da pesquisa, o pesquisador construiu vários instrumentos analíticos como memorandos, diagramas, registro das relações entre a categoria central e as subcategorias e uma história analítica global que serão o alicerce para a redação da teoria. A questão principal "é como traduzir esse material analítico de forma clara e efetiva para que outros possam se beneficiar ao utilizá-lo?" (Strauss; Corbin, c1990, p.225). Para tanto, é preciso que o pesquisador tenha construído:

(1) Uma história analítica clara. (2) A redação em nível conceitual, com a descrição em posição secundária. (3) A especificação clara das relações entre as categorias, também com o esclarecimento dos níveis de conceitualização. (4) A especificação das variações e suas condições, consequências, e o que mais forem relevantes (Strauss; Corbin, c1990, p.229).

Em geral, ao construir uma tese baseada na Teoria Fundamentada deve-se ter em vista dois procedimentos. O primeiro é o desenvolvimento de uma história analítica clara por meio dos diagramas e memorandos. O segundo, o delineamento de um esquema principal provisório que incorporará os componentes relevantes da história (Strauss; Corbin, c1990).

\section{Modelo teórico do pensamento reflexivo empregado na busca e no uso da informação no processo de comunicação científica}

O modelo teórico gerado pela pesquisa mostra as relações entre o pensamento reflexivo empregado e as atividades de busca e uso da informação. A descrição da categoria central e das categorias e processos emergentes coincidem com o que Glaser (1978) denomina Processo Social Básico, por contemplar a ação de forma integral e demonstrar as inter-relações entre elas.

Desde as primeiras análises, observou-se a influência mútua de um fenômeno sobre o outro. A identificação dessa inter-relação requeria explorar o percurso dos pesquisadores em formação, considerando seis aspectos. O primeiro, a experiência e vivências com o trabalho de pesquisa na educação básica e na graduação. O segundo, a construção do conceito de pesquisa. 0 terceiro, os sentimentos extraídos das experiências com pesquisas. O quarto, o mapeamento das competências empregadas na busca e no uso da informação na pesquisa. O quinto, a auto-avaliação das competências informacionais. Finalmente, o papel das relações sociais no processo do conhecimento.

Esta relação demonstrou ter natureza multirreferencial, caracterizada pela pluralidade dos fenômenos envolvidos e das relações entre eles. A multirreferencialidade é uma abordagem epistemológica que preconiza a leitura do fenômeno sob vários ângulos e sistemas de referência distintos (Ardoino, 1986). Inscreve-se, pois, "num universo dialético e dialetizante no qual o pensamento e o conhecimento são concebidos em contínuo movimento, num constante ir e vir, o que possibilitará a criação e com ela a construção do conhecimento" (Martins, 2004).

O modelo teórico (Figura 1), evidencia que os pesquisadores em formação, ao se depararem com uma necessidade informacional, engajam-se em atividades de busca e de uso da informação. Tais atividades requerem competências denominadas letramento informacional, que possibilitam localizar, selecionar, acessar, organizar e 
gerar conhecimento. Este, por sua vez, é influenciado pelas experiências e reflexões sobre a busca e o uso da informação, ocorridas na educação básica e na graduação, bem como os sentimentos extraídos dessas experiências.

Adicionalmente, os fatores relacionados ao processo de letramento informacional que ocorre na pós-graduação são: cultura acadêmica, atitude do professor em relação à busca e ao uso da informação, concepção de ensino-aprendizagem, infraestrutura e custos da informação e consciência do grau de competência informacional. Esses fatores são interdependentes e refletem-se na eficácia e na qualidade da busca e do uso da informação, e, consequentemente, na produção do conhecimento. Considerando que os pesquisadores em formação serão responsáveis pela formação de novos profissionais, que poderão atuar como professores e/ou pesquisadores, então, as experiências e sentimentos dos aprendizes na educação básica e graduação são influenciadas por esses profissionais.
Em suma, a influência inter-relacional dos fenômenos estudados abrange vários fenômenos de natureza cognitiva, educacional, social e ambiental. Outrossim, o modelo descrito constitui-se em uma interpretação do fenômeno central, produto dos dados coletados dos entrevistados.

\section{Limitações da abordagem}

Flick (2004) pondera que a principal limitação, grosso modo, relaciona-se com a dificuldade de diferenciação entre o método e a arte. A codificação aberta, por exemplo, pode ser aplicada a todos os trechos de um texto, gerando várias categorias que podem ser continuamente comparadas e elaboradas por meio da integração da amostragem teórica. Não existem critérios rígidos para a saturação, sendo uma decisão do pesquisador quanto à seleção e encerramento, fato este que pode resultar em muitos códigos e comparações.

\section{O pensamento reflexivo na busca e no uso da informação na comunicação científica}
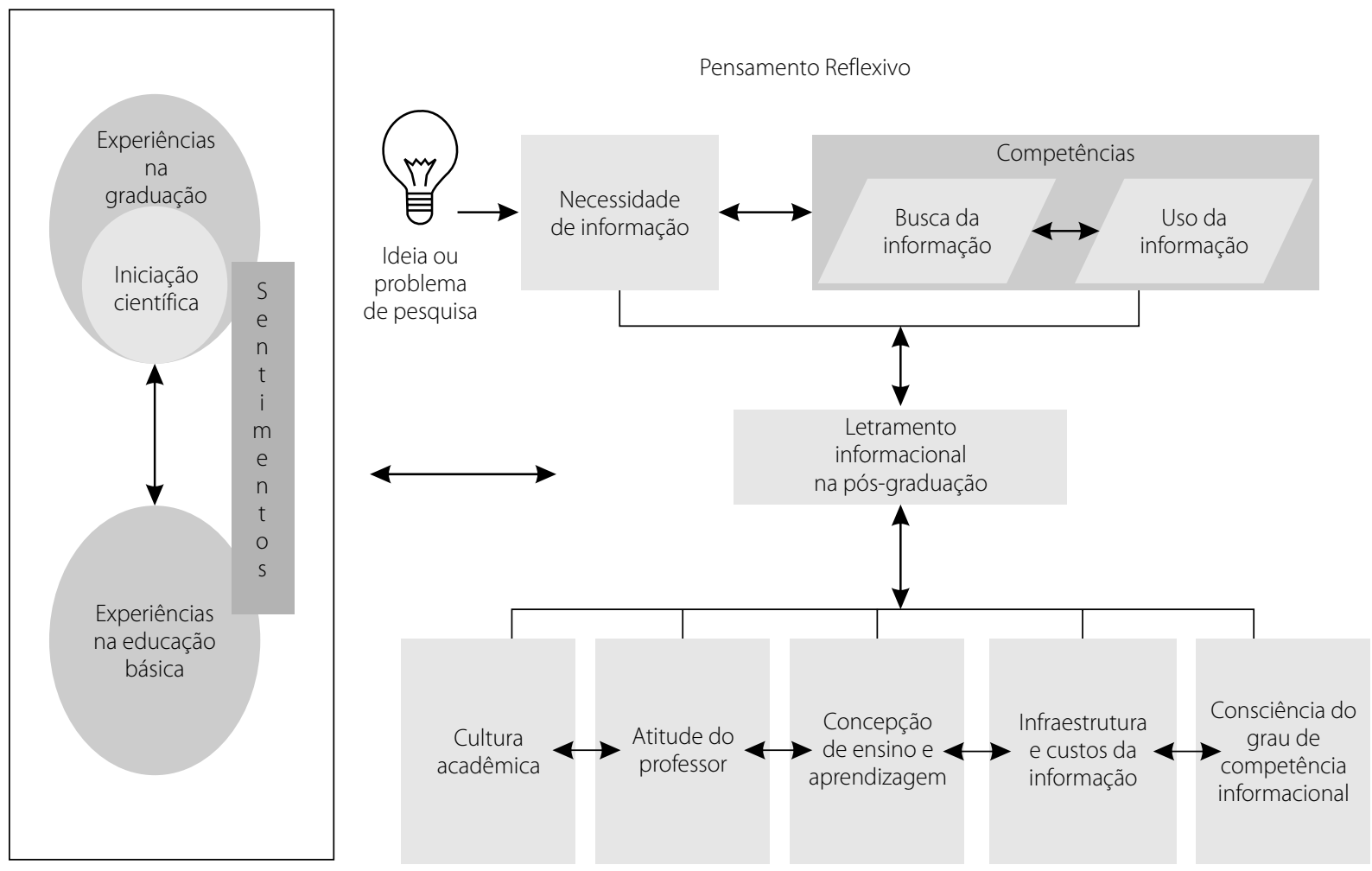

Figura 1. Modelo teórico 'o pensamento reflexivo empregado na busca e no uso da informação no processo de comunicação científica'. Fonte: Elaboração própria. 
Alvesson e Sköldberg (2000) criticam a forte resistência às influências 'intertextuais' oriundas das teorias anteriores que, também, tendem a separar a teoria da prática. Além disso, podem-se acrescentar algumas questões que suscitam cuidados em relação ao uso da metodologia, por exemplo: (1) as medidas tendem a ser mais subjetivas e, portanto, a maximização do viés do observador pode comprometer a validade do estudo; (2) os resultados, apesar de mostrarem tendências, não podem ser generalizados; (3) o trabalho é complexo, podendo aumentar os custos da pesquisa; (4) a análise dos dados subjetivos é, muitas vezes, percebida como problemática, trabalhosa, e o pesquisador deve ser muito experiente, a ponto de poder criticar a possibilidade de seu próprio viés de observação.

\section{Conclusão}

O Indicador de Atividade Reflexiva e a Teoria Fundamentada são procedimentos complexos e requerem experiência e empenho do pesquisador. Em oposição às abordagens puramente quantitativas, são flexíveis, permitindo maior aprofundamento e detalhamento dos dados, assim como possibilidade de adequação ao objeto de estudo. Nessa abordagem, não existem regras metodológicas fixas e totalmente definidas, mas diretrizes, estratégias e abordagens para as diversas fases do processo.

Por meio dos procedimentos, os pesquisadores são forçados a questionar e rever criticamente as próprias interpretações durante a pesquisa. Um argumento importante da metodologia é que múltiplas perspectivas devem ser sistematicamente procuradas durante a investigação, possibilitando, com a utilização dos procedimentos, o desenvolvimento de uma teoria de grande densidade conceitual (refere-se à riqueza do desenvolvimento de conceitos e relações) e significativa.

Os resultados mostram que a maior parte do pensamento empregado na busca e no uso da informação é do tipo não-reflexivo. Os fatores que influenciam a busca e o uso da informação dos mestrandos e doutorandos relacionam-se com o conhecimento prévio deles, construído ao longo da educação básica e do ensino superior, bem como da cultura acadêmica, a atitude dos professores (orientadores) em relação à pesquisa, a concepção de ensino-aprendizagem, infraestrutura de informação disponível e os custos de informação, além do grau de consciência que os pesquisadores em formação têm a respeito das próprias competências para buscar e usar informação.

Observa-se que, devido à falta de planejamento e implementação de programas sistematizados de letramento informacional na educação básica e superior, os indivíduos buscam e usam informação quase sempre de forma intuitiva e sem consciência do processo como um todo. Churchland (2004) argumenta que a expansão da consciência, incluindo a autoconsciência, permite a transposição do vão do senso comum para o domínio de um arcabouço conceitual consistente e articulado.

O pesquisador em formação, ao identificar as necessidades geradas por uma ideia ou problema de pesquisa, se engaja em várias atividades para buscar e usar a informação. Se adotar o pensamento reflexivo nesses processos, provavelmente os resultados obtidos serão mais eficazes, pois tal forma de pensar requer conhecimento, experiência, planejamento, sistematização e execução das ações necessárias para solução do problema, além de consciência mais ampla sobre os aspectos envolvidos na produção e disseminação do conhecimento.

\section{Referências}

ALVESSON, M.; SKÖLDBERG, K. Reflexive methodology: new vistas for qualitative research. London: SAGE, 2000. $<$ http://jardoino.club.fr/pdf/ana_multi.pdf>. Acesso em: 20 fev. 2008

CHURCHLAND, P.M. Matéria e consciência: uma introdução contemporânea à filosofia da mente. São Paulo: Unesp, 2004.
COURTRIGHT, C. Context in information behavior research. Annual Review of Information Science and Technology, v.41, p.273-306, 2007.

DEWEY, J. Como pensamos: como se relaciona o pensamento reflexivo com o processo educativo, uma reexposição. 4. ed. São Paulo: Nacional, 1979.

FLICK, U. Uma introdução à pesquisa qualitativa. Porto Alegre: Bookman, 2004. 
GASQUE, K.C.G.D. Teoria fundamentada: nova perspectiva à pesquisa exploratória. In: MUELLER, S.P.M. (Org.). Métodos para a pesquisa em ciência da informação. Brasília: Thesaurus, 2007. p.107-142

GASQUE, K.C.G.D. O pensamento reflexivo na busca e no uso da informação na comunicação científica. 2008. Tese (Doutorado em Ciência da Informação) - Universidade de Brasília, 2008.

GLASER, B.G. Theoretical sensitivity. Chicago: Sociology Press, 1978.

GLASER, B.G.; STRAUSS, A.L. The discovery of grounded theory: strategies for qualitative research. New York: Aldine de Gruyter, c1967.

MARTINS, J.B. Contribuições epistemológicas da abordagem multirreferencial para a compreensão dos fenômenos educacionais. Revista Brasileira de Educação, n.26, p. 85-94, 2004. Disponível em: <www.scielo.br/pdf/rbedu/n26/n26a06.pdf>. Acesso em: 26 fev. 2008

SILVA, M.H.S.S.; DUARTE, M.C. O diário de aula na formação de professores reflexivos: resultados de uma experiência com professores estagiários de biologia/geologia. Revista Brasileira de Pesquisa em Educação em Ciências, v.1, n.2, p.73-84, 2001. Disponível em: <http://www.fae.ufmg.br/abrapec/ revistas/N1-2/v1n2a7.pdf>. Acesso em: 22 ago. 2006.

SILVA, M.H.S.S.; DUARTE, M.C. A relação entre discurso e prática pedagógica na formação inicial dos professores. Investigações em Ensino de Ciências, v.7, n.3, 2002. Disponível em: $<$ www.if.ufrgs.br/public/ensino/vol7/n3/v7_n3_a4.htm-72k>. Acesso em: 22 ago. 2006.

STRAUSS, A.L. Qualitative analysis for social scientist. Cambridge: Cambridge University Press, 1987.

STRAUSS, A.L.; CORBIN, J. Basics of qualitative research: grounded theory, procedures and techniques. Newbury: SAGE, C1990.

ZEICHNER, K, LISTON, D. Varieties of discours in supervisory conferences. Teaching and Teacher Education, v.1, n.2, p.155-174, 1985. 